\title{
Características de solos construídos após mineração de carvão relacionadas ao processo de construção e à composição do material utilizado
}

\author{
Constructed soils characteristics after coal mining related to construction process and to material \\ composition utilized
}

\author{
Oscar Rafael Gadea Quinõnes ${ }^{\mathrm{I}}$ Alberto Vasconcellos Inda Junior ${ }^{\mathrm{II}}$ Elvio Giasson $^{\mathrm{II}}$ \\ Carlos Alberto BissaniII Deborah Pinheiro Dick ${ }^{\text {III }}$
}

\section{RESUMO}

A mineração de carvão a céu aberto envolve a remoção do solo e de camadas geológicas, que devem ser repostos na seqüência original, visando a reabilitação das áreas mineradas. Este processo altera as características originais do solo e da paisagem. Neste sentido, perfis de solos construídos há 24 e 2 anos, em duas áreas mineradas no município de Minas do Leão (RS), foram avaliados quanto ao processo e à composição dos materiais utilizados na construção. Quanto ao processo de construção, foram determinadas as características morfológicas, a densidade, a condutividade hidraulica saturada e a capacidade de infiltração de água no solo. Em relação à composição dos materiais, determinaramse granulometria, capacidade de traoca de cátions (CTC), teor de carbono orgânico (CO) e potenciais de neutralização e acidificação. Em ambas as áreas reconstituídas, o processo de construção aumentou a densidade e diminuiu a condutividade hidráulica saturada e a capacidade de infiltração de água no solo. A granulometria, a CTC e o teor de CO foram similares nas duas áreas amostradas, indicando que o processo de construção e os materiais utilizados foram semelhantes. A diminuição dos potenciais de neutralização e acidificação nos perfis de solos construídos há 24 anos indicou um avanço da sulfurização com o tempo de construção dos solos. Os solos em ambas as áreas apresentam sérias limitações para o desenvolvimento de vegetação, influindo negativamente para a recuperação dessas áreas e de áreas adjacentes.

Palavras-chave: morfologia do solo, propriedades físicas, sulfurização, potencial de acidificação.

\section{ABSTRACT}

Coal stripmining involves the removal of upper soil and geological layers, which must be relocated in a similar way that in the original profile when reconstructing the landscape. As this process changes soil and landscape characteristics, this study evaluated changes related to composition of materials and construction process in soils reconstructed 2 and 24 years ago, in Boa Vista Coal Mining, in Minas do Leão, Rio Grande do Sul, Brazil. The construction processes were evaluated by morphologic characteristics, soil density, saturated hydraulic conductivity, soil water infiltration capacity, particle size distribution, cation exchange capacity, carbon content, and neutralization and acidification potential. In both reconstructed areas, the construction process increased soil density and reduced both saturated soil hydraulic conductivity and soil water infiltration. No significant difference was found between sample sets of 2 and 24 years for particle size distribution, cation exchange capacity and carbon content, indicating that construction processes and the materials were similar. The decrease of neutralization and acidification potentials in soils built 24 years ago indicated an increase in sulfurization as time since soil reconstruction increases. Due to alterations in soils, both areas present serious limitations for vegetation development, influencing negatively the recovery of mining sites and adjacent areas.

Key words: soil morphology, physical properties, sulphurization, acidification potential.

\section{INTRODUÇÃO}

A mineração de carvão no Estado do Rio Grande do Sul dá origem a áreas de solos impactadas, como resultado do processo de extração denominado de lavra a céu aberto em faixas (stripmining) (KOPPE \& COSTA, 2002). Nesse processo, camadas de carvão

\footnotetext{
IPrograma de Pós-graduação em Ciência do Solo, Faculdade de Agronomia, Universidade Federal do Rio Grande do Sul (UFRGS), Porto Alegre, RS, Brasil.

IIDepartamento de Solos, Faculdade de Agronomia, 90001-970, Porto Alegre, RS, Brasil. E-mail: alberto.inda@ufrgs.br. *Autor para correspondência.

IIIDepartamento de Físico-Química, Instituto de Química, UFRGS, Porto Alegre, RS, Brasil.
} 
em profundidades que variam entre 25 e 40 metros são extraídas após a remoção e a estocagem em separado dos horizontes do solo, do saprolito e das camadas geológicas sobrejacentes ou intercaladas à camada de carvão, comumente denominadas de estéreis (siltitos, argilitos e folhelhos carbonosos) (PINTO, 1997; KÄMPF et al., 2000).

A legislação ambiental requer que as empresas mineradoras executem a reabilitação das áreas, de maneira que os solos construídos após a mineração proporcionem condições para o desenvolvimento vegetal (PINTO, 1997). O plano de reabilitação envolve a reposição na sequência original dos materiais estéreis e do saprolito na cava minerada, visando a reconstituição topográfica e a cobertura destes com o material solo. Entretanto, no processo de extração do carvão e na reabilitação das áreas, grandes volumes de materiais são movimentados por máquinas de grande porte, causando desestruturação, mistura e compactação dos mesmos (CIOLKOSZ et al., 1985; POTTER et al., 1988; KÄMPF et al., 2000).

O processo e a seleção dos materiais utilizados na reabilitação de áreas após a mineração de carvão influenciam muito as características dos solos construídos. Quando deficientes, a morfologia de solos construídos reflete uma sucessão irregular de camadas com cores, espessuras e texturas variáveis, geralmente descontínuas e com transições abruptas (KÄMPF et al., 1997; CAMPOS et al., 2003). A perda de estrutura determina, entre outras alterações, o aumento da densidade do solo (Ds>1,6 $\mathrm{g} \mathrm{cm}^{-3}$ ) e baixas taxas de infiltração de água no solo $\left(\mathrm{I}<5 \mathrm{~cm} \mathrm{~h}^{-1}\right)(\mathrm{KÄMPF}$ et al., 1997; GUEBERT \& GARDNER, 2001), que favorecem o escoamento superficial e a erosão hídrica.

Por sua vez, é comum que processos erosivos na superfície de solos construídos exponham resíduos de carvão contendo pirita $\left(\mathrm{FeS}_{2}\right)$, os quais, em contato com o oxigênio e a água, oxidam-se, formando ácido sulfúrico (FANNING \& FANNING, 1989), com suas conseqüentes implicações ambientais. Em perfis representativos de solos construídos de diferentes idades (cinco e dois anos) no município de Butiá-RS, KÄMPF et al. (1997) verificaram uma evolução mais intensa do processo de sulfurização nos perfis de solos com cinco anos de construção, por meio da avaliação química dos potenciais de acidificação e neutralização, os quais são relacionados à composição dos materiais utilizados na construção dos solos, porém, são alterados com a evolução dos solos.

Estudos sobre solos construídos após mineração de carvão são incipientes e há carência de dados. Considerando a tendência de ampliação da mineração de carvão no Rio Grande do Sul e que a caracterização de solos construídos em áreas mineradas permite estudar os efeitos desta atividade, este trabalho objetivou avaliar características de perfis representativos de solos construídos há 24 e dois anos no município de Minas do Leão, RS, relacionadas ao processo de construção e a composição dos materiais.

\section{MATERIAL E MÉTODOS}

O trabalho foi realizado na área da mina de carvão Boa Vista, da Companhia Rio-grandense de Mineração (CRM), situada próximo à margem do km 85 da BR 290, no município de Minas do Leão (RS). As camadas de carvão encontradas nesta área fazem parte da formação Rio Bonito, do grupo Guatá, do supergrupo Tubarão e do Permiano Superior (BRASIL, 1986).

No processo de construção dos solos na mina Boa Vista, os materiais geológicos foram repostos em camadas, por tratores de esteira, para preenchimento das cavas mineradas. Como cobertura final, foi usado material do solo natural (mistura de horizontes A, B e C), que fora removido e separado no início do processo de mineração, seguido de práticas para revegetação das áreas.

Foram selecionados perfis em duas áreas da mina reabilitadas em 1978 e 2000. Estas áreas representavam, na época de amostragem, solos construídos com idades de 24 (SA-24) e dois (SA-2) anos de construção. Na área SA-24, revegetada com Eucaliptus ssp., Pinus ssp. e gramíneas nativas, foram selecionados quatro perfis de solos construídos, identificados como: P1-24, em uma trincheira aberta num reflorestamento de eucaliptos; P2-24, em uma trincheira aberta em área de capoeira com evidência de alta erosão; P3-24 e P4-24, em trincheiras localizadas em reflorestamento de pinheiro. Na área SA-2, revegetada com gramíneas nativas e com Eucaliptus ssp. nos camaleões em curva de nível, ambas com desenvolvimento heterogêneo e incipiente, foram selecionados três perfis de solos construídos ao longo de uma seqüência em declive, identificados como: P1-2, na porção inferior; P2-2, na porção média; e P3-2, na porção superior. Adicionalmente, foram selecionados um perfil de solo natural (SN) e um perfil da coluna geológica (CG), localizados próximos a um corte de mineração recente.

A separação dos horizontes e de camadas, a caracterização morfológica e a coleta de amostras nos perfis selecionados foram realizadas conforme LEMOS \& SANTOS (1996). As análises físicas consistiram na determinação da distribuição granulométrica, utilizando-se o método do densímetro 
(EMBRAPA, 1997); condutividade hidráulica saturada (Ko), pelo método do permeâmetro de carga constante e densidade do solo, pelo método do anel volumétrico (CAUDURO \& DORFMAN, 1986); e a taxa de infiltração, determinada em locais próximos a cada perfil descrito, utilizando cilindros concêntricos (EMBRAPA, 1997). As análises químicas consistiram na determinação da capacidade de troca de cátions a pH 7,0, conforme EMBRAPA (1997); do carbono orgânico (CO) pelo método Walkley-Black modificado (TEDESCO et al., 1995); e dos potenciais de acidificação (PA) e de neutralização $(\mathrm{PN})$, pelo método do peróxido de hidrogênio adaptado por PINTO (1997).

Para análise dos resultados, foram utilizados parâmetros de estatística descritiva, obtidos por meio do programa Microsoft Excel. Com o objetivo de testar a diferença na distribuição dos parâmetros entre as amostras dos perfis representativos das áreas SA-2 e SA-24, foi aplicada a estatística U de Mann-Whitney, segundo KÄMPF et al. (1997), utilizando-se o programa STATISTIX7 (2000).

\section{RESULTADOS E DISCUSSÃO}

\section{Características morfológicas}

As características morfológicas do solos natural (SN), da coluna geológica (CG) e de perfis selecionados de solos construídos são apresentadas na tabela 1.

O perfil do SN foi classificado, segundo o Sistema Brasileiro de Classificação de Solos (EMBRAPA, 2006), como Plintossolo Argilúvico Distrófico abrúptico. Neste, a textura variou de franco argilosa (295 $\mathrm{g} \mathrm{kg}^{-1}$ de argila), no horizonte superficial de coloração bruno escuro, a muito argilosa (>635 $\mathrm{g} \mathrm{kg}^{-1}$ de argila), nos horizontes subsuperficiais, onde a coloração da matriz do solo variou de bruno a bruno acinzentado escuro com presença de segregações de ferro (plintita) de coloração bruno forte (Tabelas 1 e 2). A estrutura variou de moderada a fracamente desenvolvida, em blocos subangulares, com tamanhos entre pequeno e grande. A CG foi dividida em nove camadas até a profundidade aproximada de 20 metros, as quais foram separadas com base na cor, textura e coerência dos materiais (Tabelas 1 e 2). Excetuando a camada C5, de textura franco argilosa (310 $\mathrm{kg}^{-1}$ de argila), as demais apresentaram textura entre argila siltosa e muito argilosa, com conteúdos somados de argila e silte superiores a $950 \mathrm{~g} \mathrm{~kg}^{-1}$. O topo da CG é constituído por um argilito de coloração variegada (saprolito), seguido por uma camada de argilito bruno amarelado, a partir do qual se sucedem as demais camadas com predomínio de cores acinzentadas.
As características morfológicas dos solos construídos nas áreas SA-24 e SA-2 resultam de materiais semelhantes àqueles presentes no $\mathrm{SN}$ da área minerada, na CG e no solo de áreas adjacentes, utilizados no processo de construção. Em ambas as áreas, os materiais foram dispostos em camadas ou horizontes com espessuras variáveis entre 4 e $58 \mathrm{~cm}$, normalmente com transições abruptas ou claras e planas ou onduladas, distinguidas pela cor e textura dos materiais (Tabela 1). A camada superficial dos perfis foi denominada de $\mathrm{A}$ e as camadas subsuperficiais de C.

Na área SA-24 a camada A dos perfis de solos descritos variou entre 15 e $67 \mathrm{~cm}$ de espessura, sendo formada por material de solo argiloso a muito argiloso, com coloração variável entre bruno avermelhado escuro (5 YR 3/3) na superfície, devido ao elevado teor de CO, a vermelho (2,5 YR 4/6), conforme aumenta a profundidade desta camada. A permanência deste material utilizado como cobertura final no processo de construção do solo na área SA-24 devese ao relevo plano e ao estabelecimento de cobertura vegetal densa na maior parte da área. Entretanto, características semelhantes a este material não foram constatadas em nenhum dos horizontes do SN descrito (Tabela 1), indicando que materiais de solo de outros locais foram utilizados como cobertura final no processo de construção da área SA-24. Nos perfis com maior teor de CO na superfície, localizados nos reflorestamentos (ex. P1-24) (Tabela 2), verificou-se a formação de unidades estruturais em blocos subangulares com grau de desenvolvimento moderado, confirmando a atuação de processos pedogenéticos ao longo do tempo, conforme constatado em solos avaliados por KÄMPF et al. (1997) e SENCINDIVER \& AMMONS (2000).

$\mathrm{Na}$ área SA-2, a espessura da camada A do perfil P1-2, localizado na porção inferior e plana da toposeqüência, foi semelhante a dos perfis descritos na área SA-24. Nos demais perfis, esta camada foi pouco espessa $(<15 \mathrm{~cm})$ e, muitas vezes, ausente com afloramento de material geológico de camadas subjacentes devido ao desgaste causado pelo processo erosivo, favorecido pela escassa cobertura vegetal do solo e pela declividade na área SA-2. A morfologia do material da camada A nesta área, constituída por mistura de materiais de textura argilosa a muito argilosa, foi similar ao material descrito no horizonte $\mathrm{BC}$ e $\mathrm{C}$ do solo natural, fato indicativo de que os horizontes $\mathrm{A}$ e $\mathrm{B}$, utilizados como cobertura final no processo de construção, foram removidos pela erosão. Em adição, a estrutura dessa camada mostrou-se maciça ou em grãos simples, com ausência de unidades estruturais. 
Tabela 1 - Características morfológicas do solo natural, da coluna geológica e de perfis de solos construídos selecionados, com dois (P1-2 e P3-2) e 24 (P1-24 e P2-24) anos de construção.

\begin{tabular}{|c|c|c|c|}
\hline $\begin{array}{l}\text { Horizonte/ } \\
\text { camada }\end{array}$ & Prof.(cm) & Classe textural & Cor \\
\hline A & $0-25$ & Franca argilosa & Bruno escuro (7,5 YR 3/2) \\
\hline B & -47 & Muito argilosa & Cinzento avermelhado escuro (5 YR 4/2); Bruno forte (7,5 YR 4/6, mosqueado) \\
\hline Bf1 & -73 & Muito argilosa & Bruno (10 YR 4/3); Bruno forte (7,5 YR 4/6, mosqueado) \\
\hline Bf2 & -96 & Muito argilosa & Bruno acinzentado escuro (10 YR 4/2); Bruno forte (7,5 YR 4/6, mosqueado) \\
\hline BCf & $-130^{+}$ & Muito argilosa & $\begin{array}{l}\text { Cinzento avermelhado (2,5 Y 5/1); Bruno forte (7,5 R 4/6, mosqueado) } \\
\text { Coluna geológica }\end{array}$ \\
\hline C 1 & $200-450$ & Muito argilosa & $\begin{array}{l}\text { Variegado Cinzento (5 Y 6/1), Vermelho (2,5 YR 4/6) e Amarelo brunado (10 YR } \\
6 / 8 \text { ) }\end{array}$ \\
\hline C 2 & -630 & Muito argilosa & Bruno amarelado (10 YR 5/8) \\
\hline C 3 & -970 & Argila siltosa & Cinzento escuro (5 Y 4/1) \\
\hline C 4 & -995 & Argila siltosa & Cinzento claro (10 YR 7/1) \\
\hline C 5 & -1095 & Franca argilosa & Preto $(2,5$ Y 2,5/1) \\
\hline C 6 & -1375 & Argila & Cinzento escuro (2,5 Y 4/1) \\
\hline C 7 & -1625 & Muito argilosa & Cinzento muito escuro (2,5 Y 3/1) \\
\hline C 8 & -1625 & Argila siltosa a Argila & Bruno oliváceo (2,5 Y 4/4) \\
\hline C 9 & $-1975^{+}$ & Argila siltosa & $\begin{array}{l}\text { Cinzento oliváceo (5 Y 4/2) } \\
\text { Perfil P1-2 }\end{array}$ \\
\hline A 1 & $0-58$ & Muito argilosa & Cinzento avermelhado (2,5 Y 5/1); Bruno forte (7,5 R 4/6, mosqueado) \\
\hline C 1 & -75 & Muito argilosa & Bruno amarelado claro (2,5 Y 6/4) \\
\hline C 2 & -87 & Argila arenosa & Cinzento escuro (2,5 Y 4/0); Vermelho (2,5 YR 4/6, mosqueado) \\
\hline C 3 & $-100^{+}$ & Muito argilosa & $\begin{array}{l}\text { Bruno oliváceo (2,5 Y 4,5/4) } \\
\text { Perfil P3-2 }\end{array}$ \\
\hline A 1 & $0-14$ & Muito argilosa & Bruno acinzentado escuro (10 YR 4/2) \\
\hline C 1 & -34 & Muito argilosa & Variegada Bruno acinzentado escuro (10 YR 4/2) e Cinzento oliváceo (5 Y 4/2) \\
\hline C 2 & -48 & Argila siltosa & Cinzento oliváceo (5 Y 4/2) \\
\hline C 3 & -61 & Muito argilosa & Cinzento (7,5 YR 5/1); Amarelo oliváceo (2,5 Y 6/8, mosqueado) \\
\hline C 4 & $-75^{+}$ & Franco argilo arenosa & $\begin{array}{l}\text { Preto (2,5 Y 2/0) } \\
\text { Perfil P1-24 }\end{array}$ \\
\hline A 1 & $0-4$ & Argila & Bruno avermelhado escuro (5 YR 3/3) \\
\hline A2 & -15 & Argila & Vermelho escuro (2,5 YR 3/6) \\
\hline C 2 & -67 & Muito argilosa & Bruno avermelhado (2,5 YR 4/4); Bruno avermelhado (5 YR 4/4, mosqueado) \\
\hline C 3 & $-98^{+}$ & Muito argilosa & $\begin{array}{l}\text { Vermelho (2,5 YR 4/6), Bruno oliváceo claro (2,5 Y 5/6, mosqueado) } \\
\text { Perfil P2-24 }\end{array}$ \\
\hline A 1 & $0-26$ & Argila & Bruno avermelhado escuro (2,5 YR 3/4) \\
\hline C 1 & -61 & Muito argilosa & Cinzento escuro (5 YR 4/1); Vermelho (2,5 YR 5/6, mosqueado) \\
\hline C 2 & -69 & Muito argilosa & Preto (2,5 Y 2/0) \\
\hline C 3 & $-96^{+}$ & Muito argilosa & Cinzento claro (2,5 Y 7/1) \\
\hline
\end{tabular}

Em ambas as áreas, as camadas subsuperficiais dos solos construídos (camadas C) apresentaram estrutura maciça. Ocorre uma expressiva variedade de cores na matriz, como preto (2,5 Y 2/0), cinzento escuro (5 YR 4/1, 7,5 YR 3,5/0 e 10 YR 4/1), cinzento (2,5 Y 5,5/0), cinzento claro (2,5 Y 7/1), bruno amarelado (10 YR 5/8), bruno avermelhado escuro (2,5 YR 3/5) e vermelho (2,5 YR 4/6), e nos mosqueados, como bruno acinzentado (2,5 Y 5/6), bruno avermelhado (5 YR 4/4), bruno oliváceo claro (2,5 Y 4,5/2-4) e vermelho (2,5 YR 4/6) (Tabela 1). Estas cores das camadas C refletem a composição mineral da CG (argilitos, siltitos, folhelhos carbonosos e o próprio carvão), bem como de minerais formados a partir da oxidação da pirita e sulfurização desses solos (KÄMPF et al., 1997). A seqüência de disposição dos materiais apresentou uma ampla variação nos perfis descritos nas áreas de solos construídos, verificando-se inclusive a presença de materiais de SN dispostos em subsuperfície, subjacentes a camadas de materiais geológicos.

\section{Características físicas}

As características físicas do SN, da CG e de perfis selecionados de solos construídos nas áreas SA- 
Tabela 2 - Características físicas e químicas do solo natural, da coluna geológica e e de perfis de solos construídos selecionados, com dois (P1-2 e P3-2) e 24 (P1-24 e P2-24) anos de construção.

\begin{tabular}{|c|c|c|c|c|c|c|c|c|c|c|c|c|}
\hline $\begin{array}{l}\text { horizonte/ } \\
\text { camada }\end{array}$ & $\begin{array}{l}\text { prof. } \\
\text { cm }\end{array}$ & areia & $\begin{array}{l}\text { silte } \\
\text {-g kg-1 }\end{array}$ & argila & silte/argila & $\begin{array}{c}\mathrm{CTC}_{\mathrm{pH} 7}{ }^{1} \\
\mathrm{cmol}_{\mathrm{c}} \mathrm{kg}^{-1}\end{array}$ & $\begin{array}{c}\mathrm{CO}^{2} \\
\mathrm{~g} \mathrm{~kg}^{-1}\end{array}$ & $\begin{array}{l}\mathrm{PN}^{3} \\
\mathrm{~kg} \mathrm{C}\end{array}$ & $\begin{array}{l}\mathrm{PA}^{4} \\
\mathrm{O}_{3} \mathrm{t}^{-1}\end{array}$ & PN-PA & $\begin{array}{c}\mathrm{Ds}^{5} \\
\mathrm{~T} \mathrm{~m}{ }^{-3}\end{array}$ & $\begin{array}{c}\mathrm{Ko}^{6} \\
\mathrm{~cm} \mathrm{~h}^{-1} 10^{-6}\end{array}$ \\
\hline \multicolumn{13}{|c|}{ Solo natural } \\
\hline A & $0-25$ & 426 & 279 & 295 & 0,95 & 25,7 & 18 & - & - & - & - & - \\
\hline B & -47 & 110 & 190 & 700 & 0,27 & 42,9 & 14 & - & - & - & - & - \\
\hline Bf1 & -73 & 152 & 198 & 650 & 0,30 & 42,2 & 6 & - & - & - & - & - \\
\hline Bf2 & -96 & 148 & 192 & 660 & 0,29 & 29,2 & 4 & - & - & - & - & - \\
\hline BCf & -130 & 181 & 184 & 635 & 0,29 & 25,1 & 2 & - & - & - & - & - \\
\hline \multicolumn{13}{|c|}{ Coluna geológica } \\
\hline C 1 & -450 & 5 & 210 & 785 & 0,27 & 41,1 & 1 & 6,7 & 3,3 & 3,4 & - & - \\
\hline C 2 & -630 & 5 & 270 & 725 & 0,37 & 34,5 & 0,1 & 6,7 & 3,2 & 3,5 & - & - \\
\hline C 3 & -970 & 44 & 421 & 535 & 0,79 & 34,4 & 386 & 1,5 & 3,5 & $-2,0$ & - & - \\
\hline C 4 & -995 & 40 & 450 & 510 & 0,88 & 50,2 & 6 & 7,8 & 18,2 & $-10,4$ & - & - \\
\hline C 5 & -1095 & 369 & 321 & 310 & 1,04 & 36,7 & 124 & 13,2 & 27,5 & $-14,3$ & - & - \\
\hline C 6 & -1375 & 7 & 348 & 645 & 0,54 & 35,8 & 32 & 13,1 & 5,5 & 7,6 & - & - \\
\hline C 7 & -1625 & 14 & 326 & 660 & 0,49 & 37,9 & 18 & 17 & 3,4 & 13,6 & - & - \\
\hline C 8 & -1625 & 13 & 402 & 585 & 0,69 & 36,4 & 3 & 34,6 & 5,4 & 29,2 & - & - \\
\hline C 9 & -1975 & 23 & 447 & 530 & 0,84 & 24,2 & 31 & 44,3 & 3,4 & 40,9 & - & - \\
\hline \multicolumn{13}{|c|}{ Perfil P1-2 } \\
\hline A 1 & $0-58$ & 147 & 333 & 520 & 0,64 & 19,2 & 3 & 8,2 & 1,4 & 6,8 & 1,7 & 2,8 \\
\hline C 1 & -75 & 20 & 260 & 720 & 0,36 & 27,3 & 0,1 & 16,0 & 8,8 & 7,2 & 1,8 & 2,8 \\
\hline C 1 & -75 & 14 & 206 & 780 & 0,26 & 36,0 & 2 & 13,2 & 4,7 & 8,5 & - & - \\
\hline C 2 & -87 & 660 & 23 & 317 & 0,07 & 21,8 & 7 & 12,4 & 4,9 & 7,5 & - & - \\
\hline C 2 & -87 & 400 & 283 & 317 & 0,89 & 11,0 & 221 & 11,4 & 3,5 & 7,9 & - & - \\
\hline C 3 & -100 & 28 & 362 & 610 & 0,59 & 33,3 & 4 & 10,7 & 5,2 & 5,5 & 2,0 & 2,8 \\
\hline \multicolumn{13}{|c|}{ Perfil P3-2 } \\
\hline A 1 & $0-14$ & 86 & 164 & 750 & 0,22 & 56,4 & 15 & 8,5 & 10,2 & $-1,7$ & 1,8 & 2,8 \\
\hline C 1 & -34 & 73 & 262 & 665 & 0,39 & 26,4 & 11 & 14,4 & 10,4 & 4,0 & 2,0 & 0,0 \\
\hline C 2 & -48 & 107 & 493 & 400 & 1,23 & 12,1 & 4 & 14,5 & 4,8 & 9,7 & 2,1 & 0,0 \\
\hline C 3 & -61 & 8 & 207 & 785 & 0,26 & 16,6 & 1 & 13,6 & 2,4 & 11,3 & 2,3 & 2,8 \\
\hline C 4 & -75 & 575 & 103 & 322 & 0,32 & 19,7 & 39 & 14,0 & 14,2 & $-0,2$ & - & - \\
\hline \multicolumn{13}{|c|}{ Perfil P1-24 } \\
\hline A 1 & $0-4$ & 170 & 370 & 460 & 0,80 & 30,7 & 103 & 4,7 & 0,9 & 3,8 & - & - \\
\hline A2 & -15 & 269 & 186 & 545 & 0,34 & 17,4 & 13 & 18,5 & 1,2 & 17,3 & 1,9 & 4,2 \\
\hline C 2 & -67 & 147 & 138 & 715 & 0,19 & 22,6 & 10 & 2,6 & 1,2 & 1,4 & 2,0 & 7,8 \\
\hline C 2 & -67 & 208 & 177 & 615 & 0,29 & 18,1 & 7 & - & - & - & - & - \\
\hline C 3 & -98 & 269 & 181 & 550 & 0,33 & 14,2 & 8 & 6,0 & 1,5 & 4,6 & 2,2 & 2,8 \\
\hline C 4 & -115 & 23 & 292 & 685 & 0,43 & 14,7 & 4 & 6,0 & 1,2 & 4,8 & - & - \\
\hline \multicolumn{13}{|c|}{ Perfil P2-24 } \\
\hline A 1 & $0-26$ & 319 & 186 & 495 & 0,38 & 16,7 & 14 & 1,2 & 0,9 & 0,3 & 1,8 & 20,3 \\
\hline C 1 & -61 & 37 & 303 & 660 & 0,46 & 18,8 & 8 & 2,1 & 1,5 & 0,7 & 1,8 & 0,0 \\
\hline C 2 & -69 & 62 & 283 & 655 & 0,43 & 21,0 & 12 & 9,4 & 1,5 & 7,9 & 2,0 & 0,0 \\
\hline C 3 & -96 & 13 & 322 & 665 & 0,48 & 18,6 & 0,1 & 9,5 & 1,2 & 8,3 & - & - \\
\hline
\end{tabular}

${ }^{1} \mathrm{CTC}_{\mathrm{pH}}$ - Capacidade de troca de cátions em pH 7; ${ }^{2}$ Carbono orgânico (CO); ${ }^{3}$ Potencial de neutralização; ${ }^{4}$ Potencial de acidificação; ${ }^{5}$ Densidade do solo; ${ }^{6}$ Condutividade hidráulica saturada.

2 e SA-24 são apresentados na tabela 2. Os valores médios dessas características para o conjunto das amostras dos perfis de solos construídos em cada área são apresentados na tabela 3 . O teste U de MannWhitney mostrou que não ocorrem diferenças significativas $(\mathrm{P}>0,01)$ entre as áreas SA-24 e SA-2 para as frações granulométricas areia, silte e argila, as quais relacionam-se à composição dos materiais utilizados na construção e para as características densidade do solo (Ds) e condutividade hidráulica saturada (Ko) 
Tabela 3 - Parâmetros estatísticos de características relacionadas à composição do material utilizado e ao processo de construção dos solos.

\begin{tabular}{|c|c|c|c|c|c|c|c|c|}
\hline Atributos do solo & $\begin{array}{l}\text { Idade } \\
\text { anos }\end{array}$ & Média & $\mathrm{DP}^{1}$ & $\begin{array}{c}\mathrm{CV}^{2} \\
\%\end{array}$ & Mínimo & Máximo & $\mathrm{U}^{3}$ & $\mathrm{p}$ \\
\hline \multicolumn{9}{|c|}{ Características relacionadas à composição do material } \\
\hline \multirow{2}{*}{ Areia, $\mathrm{g} \mathrm{kg}^{-1}$} & 2 & 146 & 196,76 & 134,8 & 8 & 660 & 140,0 & 0,0805 \\
\hline & 24 & 272 & 259,75 & 95,7 & 4 & 700 & 274,0 & \\
\hline \multirow{2}{*}{ Silte, $\mathrm{g} \mathrm{kg}^{-1}$} & 2 & 299 & 145,59 & 48,7 & 23 & 645 & 265,5 & 0,1275 \\
\hline & 24 & 235 & 107,35 & 45,7 & 9 & 470 & 148,5 & \\
\hline \multirow{2}{*}{ Argila, g kg ${ }^{-1}$} & 2 & 555 & 165,96 & 29,9 & 315 & 785 & 241,0 & 0,3787 \\
\hline & 24 & 493 & 198,02 & 40,1 & 129 & 715 & 173,0 & \\
\hline \multirow{2}{*}{$\mathrm{CTC}_{\mathrm{pH}}, \mathrm{cmol}_{\mathrm{c}} \mathrm{kg}^{-1}$} & 2 & 22,8 & 10,98 & 48,1 & 10,0 & 56,4 & 229,5 & 0,7411 \\
\hline & 24 & 23,7 & 14,46 & 61,0 & 13,8 & 79,2 & 202,5 & \\
\hline \multirow{2}{*}{$\mathrm{CO}, \mathrm{g} \mathrm{kg}^{-1}$} & 2 & 20 & 51,1 & 262,1 & 0,01 & 22,1 & 184,5 & 0,4298 \\
\hline & 24 & 18 & 34,4 & 192,2 & 0,01 & 14,7 & 247,5 & \\
\hline \multirow{2}{*}{$\mathrm{PN}, \mathrm{kg} \mathrm{CaCO} \mathrm{C}^{-1}$} & 2 & 12,5 & 2,50 & 20,1 & 8,2 & 16,0 & 84,0 & 0,0035 \\
\hline & 24 & 6,7 & 5,33 & 79,9 & 1,2 & 18,5 & 15,0 & \\
\hline \multirow{2}{*}{$\mathrm{PA}, \mathrm{kg} \mathrm{CaCO} \mathrm{C}^{-1}$} & 2 & 6,4 & 3,95 & 61,6 & 1,36 & 14,2 & 106,0 & 0,0000 \\
\hline & 24 & 1,3 & 0,25 & 19,7 & 0,90 & 1,6 & 4,0 & \\
\hline \multicolumn{9}{|c|}{ Características relacionadas ao processo de construção } \\
\hline \multirow{2}{*}{ Ds, $\mathrm{g} \mathrm{cm}^{3}$} & 2 & 2,04 & 0,22 & 10,8 & 1,7 & 2,4 & 100,0 & 0,0953 \\
\hline & 24 & 1,90 & 0,15 & 7,9 & 1,7 & 2,2 & 43,0 & \\
\hline \multirow{2}{*}{$\mathrm{Ko}, \mathrm{cm} \mathrm{h}^{-1}$} & 2 & 0,22 & 0,33 & 150,0 & 0,0 & 1,1 & 54,5 & 0,3261 \\
\hline & 24 & 2,53 & 3,45 & 136,4 & 0,0 & 9,6 & 88,5 & \\
\hline
\end{tabular}

${ }^{1}$ Desvio padrão; ${ }^{2}$ Coeficiente de variação; ${ }^{3}$ Teste Mann-Whitney.

relacionadas ao processo de construção dos solos (Tabela 3). Estes resultados indicam que os materiais utilizados e o processo de construção foram similares em ambas as áreas estudadas.

A granulometria variou irregularmente com a profundidade dos perfis em ambas as áreas, indicando uma superposição de materiais heterogêneos durante o processo de construção (Tabela 2). O predomínio da fração argila nas camadas deve-se à constituição dos materiais utilizados na construção (Tabela 2), compostos em grande parte por rochas pelíticas sílticoargilosas (PINTO, 1997), confirmando observações anteriores em áreas reconstituídas na mesma região (KÄMPF et al., 2000). Por outro lado, a ocorrência de camadas com predomínio da fração areia (ex. C2 do P12, C4 do P3-2) (Tabela 2) bastante superior a do horizonte A do SN sugere que materiais externos à área minerada foram utilizados na construção desses solos, mesmo considerando que pequenas diferenças na distribuição granulométrica entre camadas de solos construídos e nos materiais utilizados (SN e CG) resultam da mistura destes durante a recomposição das áreas mineradas (POTTER et al., 1988).

A Ds nas camadas variou entre 1,7 e $2,4 \mathrm{~g}$ $\mathrm{cm}^{-3}$, com valores médios de 1,90 e $2,04 \mathrm{~g} \mathrm{~cm}^{-3}$, respectivamente, para as áreas SA-24 e SA-2, indicando uma alta compactação dos solos, causada pelo tráfego intenso de máquinas pesadas durante o processo de remoção, transporte e construção (POTTER et al., 1988) e favorecida pela textura argilosa dos materiais utilizados (SNARSKI et al., 1981). Nas duas áreas, esta condição do solo restringiu a condutividade hidráulica saturada (Ko) e a taxa de infiltração da água no solo (I). Para a Ko, os valores médios de 2,53 e $0,22 \mathrm{~cm} \mathrm{~h}^{-1}$ indicaram um enquadramento nas classes de Ko moderada alta e moderada baixa (USDA, 1993), respectivamente, para os perfis de solos das áreas SA24 e SA-2. Esta diferença na Ko média entre as áreas, mesmo que não significativa a ponto de indicar processos de construção distintos conforme indicou o teste U de Mann-Whitney ( $\mathrm{P}=0,3261$ ) (Tabela 3), pode ser resultado do efeito do desenvolvimento das raízes e da atividade biológica devido à contribuição da matéria orgânica ao longo do tempo, indicado por maiores valores de Ko nas camadas superficiais dos perfis descritos na área reconstituída há 24 anos (ex. A1 do P2-24, Ho=7,3cm h-1). Portanto, a determinação da taxa de infiltração da água colaborou , sendo que o valor médio dos ensaios realizados em cada área aumentou de $4,5 \mathrm{~cm} \mathrm{~h}^{-1}\left(\mathrm{I}=0,635 \mathrm{t}^{0,1852}\right)$ na SA-2 para 7,4cm $\mathrm{h}^{-1}\left(\mathrm{I}=0,527 \mathrm{t}^{0,4963}\right)$ na SA-24, são ambos inferiores à taxa de infiltração no solo natural, de $12,1 \mathrm{~cm} \mathrm{~h}^{-1}$ 
$\left(\mathrm{I}=1,089 \mathrm{t}^{0,3630}\right)$. Estes resultados de I assemelham-se aos observados por KÄMPF et al. (1997) e GUEBERT \& GARDNER (2001) e, associados à acentuada declividade do terreno na SA-2, favoreceram a intensa erosão verificada principalmente na área SA-2, dificultando o estabelecimento da cobertura vegetal.

\section{Características químicas}

As características químicas dos materiais utilizados na construção (SN e CG) e de perfis selecionados de solos construídos nas áreas SA-24 e SA-2 são apresentados na tabela 2 . A capacidade de troca de cátions (CTC) variou de 25,1 a 42,9 $\mathrm{cmol}_{\mathrm{C}} \mathrm{kg}^{-1} \mathrm{e}$ de 24,2 a $50,2 \mathrm{cmol}_{\mathrm{c}} \mathrm{kg}^{-1}$, respectivamente, para o SN e a CG. No horizonte A do SN, o conteúdo de carbono orgânico (CO) foi baixo $\left(18 \mathrm{~g} \mathrm{~kg} \mathrm{~kg}^{-1}\right)$ e diminuiu em profundidade. Na CG predominaram camadas com baixos conteúdos de CO $\left(\leq 32 \mathrm{~g} \mathrm{~kg}^{-1}\right)$ intercaladas por duas camadas com elevados conteúdos de CO (124g $\mathrm{kg}^{-1}$ para C5 e 386 $\mathrm{g} \mathrm{kg}^{-1}$ para C3). Na CG, também foram variáveis o potencial de neutralização (PN) $\left(1,5<\mathrm{PN}<44,3 \mathrm{~kg} \mathrm{CaCO}_{3} \mathrm{t}^{-1}\right)$ e o potencial de acidificação (PA) $\left(3,2<\mathrm{PA}<27,5 \mathrm{~kg} \mathrm{CaCO}_{3} \mathrm{t}^{-1}\right)$, os quais indicaram um potencial líquido de neutralização negativo em três camadas da CG (C3, C4 e C5) (Tabela 2).

Nos perfis de solos construídos, as características químicas mostraram uma tendência errática com o aumento da profundidade nas áreas SA24 e SA-2 (Tabela 2), confirmando a caracterização morfológica destes e estudos anteriores em áreas reconstituídas após mineração (KÄMPF et al., 2000; CAMPOS et al., 2003). Os valores médios dessas características para o conjunto das camadas dos solos construídos em cada área são apresentados na tabela 3. O teste U de Mann-Whitney mostrou que a CTC, com valores médios de 23,7 e 22,8 $\mathrm{cmol}_{\mathrm{c}} \mathrm{kg}^{-1}$, e o $\mathrm{CO}$, com valores médios de 18 e $2 \mathrm{~g} \mathrm{~kg}^{-1}$, respectivamente, para as áreas SA-24 e SA-2, não diferem significativamente $(\mathrm{P}>0,01)$ entre as camadas nessas áreas, independente da idade de construção dos solos, confirmando a similaridade entre os materiais utilizados na construção dos solos nas duas áreas.

Por outro lado, o PN, determinado na litologia da região pela presença de minerais tamponantes como carbonatos e esmectitas (PINTO, 1997), e o PA, relacionado com a presença de pirita $\left(\mathrm{FeS}_{2}\right)$, diferiram significativamente $(\mathrm{P}<0,01)$ entre os perfis avaliados em SA-24 e SA-2. Essas considerações confirmam observações de KÄMPF et al. (1997) e KÄMPF et al. (2000) de que, embora esses atributos (PA e PN) representem, originalmente, a composição dos materiais de origem de solos construídos, eles são alterados com a evolução dos mesmos ao longo do tempo. O PA, com valores médios de 1,3 e 6,4kg $\mathrm{CaCO}_{3}$ $\mathrm{t}^{-1}$ para as camadas das áreas SA-24 e SA-2, respectivamente, é o resultado da oxidação gradativa da pirita presente nos solos construídos quando exposta à presença de água e ar, conforme identificada. A redução dos valores médios de $\mathrm{PN}$ da área SA-2 para a SA-24, de 12,5 para $6,7 \mathrm{~kg} \mathrm{CaCO}_{3} \mathrm{t}^{-1}$, é igualmente resultado da dissolução protônica dos minerais tamponantes em razão da acidificação gerada pela oxidação da pirita, encontrada no material de formação dos solos. Os resultados sugerem que o processo de sulfurização encontra-se em estádio mais avançado nos solos construídos da área SA-24.

As características dos solos construídos avaliadas neste estudo indicam sérias deficiências no processo de construção dos solos, cujas conseqüências ambientais desfavoráveis são a restrição ao desenvolvimento vegetal adequado, o processo de erosão acelerado e a contaminação do solo e da água. A prévia seleção dos materiais a serem utilizados na construção dos solos, bem como a disposição uniforme dos mesmos durante o processo de construção, são medidas que devem ser consideradas na reabilitação de áreas após a mineração de carvão a céu aberto.

\section{CONCLUSÕES}

O processo de construção e os materiais utilizados alteraram fortemente as características morfológicas e físicas dos solos construídos comparativamente ao solo natural em ambas as áreas reconstituídas após a mineração de carvão.

O processo de construção acarretou aumento da densidade do solo e diminuição da condutividade hidráulica saturada e capacidade de infiltração de água no solo. Estas características, da mesma forma que a distribuição granulometria, a CTC, a pH7 e o teor de carbono orgânico, não diferiram significativamente entre os perfis amostrados, indicando que o processo de construção e os materiais utilizados foram similares em ambas as áreas reabilitadas.

A diminuição significativa dos potenciais de neutralização e acidificação na população dos solos construídos há 24 anos em relação a dos solos construídos há dois anos indicou a atuação e o avanço do processo de sulfurização com o tempo de construção dos solos.

As deficiências relativas ao processo de construção demonstram que os solos em ambas as áreas apresentam sérias limitações para o desenvolvimento de vegetação de cobertura, influindo negativamente para a recuperação dessas áreas e de áreas adjacentes. 


\section{APRESENTAÇÃO E AGRADECIMENTOS}

Parte da Dissertação de Mestrado em Ciência do Solo do primeiro autor apresentado ao Programa de Pósgraduação em Ciência do Solo, Universidade Federal do Rio Grande do Sul (UFRGS). Agradecemos ao Conselho Nacional de Desenvolvimento Científico e Tecnológico (CNPq) e a Companhia Riograndense de Mineração (CRM) pelo financiamento. E a Adão Luiz dos Santos, laboratorista do Departamento de Solos da UFRGS pela ajuda.

\section{REFERÊNCIAS}

BRASIL. Instituto Brasileiro de Geografia e Estatística. Levantamento de recursos naturais. Rio de Janeiro, 1986 V.33. 796p.

CAMPOS, M.L. et al. Avaliação de três áreas de solo construído após mineração de carvão a céu aberto em Lauro Müller, Santa Catarina. Revista Brasileira de Ciência do Solo, v.27, p.1123-1137, 2003.

CAUDURO, F.A.; DORFMAN, R. Manual de ensaios de laboratório e de campo para irrigação e drenagem. Porto Alegre: PRONI, 1986. 216p.

CIOLKOSZ, E.J. et al. Characteristics, genesis, and classification of Pennsylvania minesoils. Soil Science, v.139, p.232-238, 1985.

EMBRAPA. Centro Nacional de Pesquisa de Solos. Sistema Brasileiro de Classificação de Solos. Brasília, 2006. 412p.

EMBRAPA. Serviço Nacional de Levantamento e Conservação de Solos. Manual de métodos de análise de solo. 2.ed. Rio de Janeiro, 1997. 212p.

FANNING, D.S.; FANNING, M.C.B. Soil: morphology, genesis and classification. New York: J. Willey, 1989. 395p.

GUEBERT, M.D.; GARDNER, T.W. Macropore flow on a reclaimed surface mine: infiltration and hillslope hydrology. Geomorphology, v.39, p.151-169, 2001.

KÄMPF, N. et al. Propriedades, pedogênese e classificação de solos construídos em áreas de mineração na bacia carbonífera do baixo Jacuí (RS). Revista Brasileira de Ciência do Solo, v.21, p.79-88, 1997.

KÄMPF, N. et al. Solos construídos em áreas de mineração da Bacia Carbonífera. In: CENTRO DE ECOLOGIA - UFRGS. Carvão e meio ambiente. Porto Alegre: UFRGS, 2000. Cap.17, p.596-640.

KOPPE, J.C.; COSTA, J.F.C. Mineração. In: TEIXEIRA, E.C. Meio ambiente e carvão: impactos da exploração e utilização. Porto Alegre: FEPAM, 2002. p.15-27.

LEMOS, R.C.; SANTOS, R.D. Manual de descrição e coleta de solos no campo. 3.ed. Campinas: Sociedade Brasileira de Ciência do Solo, 1996. 84p.

PINTO, L.F.S. Potencial de acidificação e neutralização dos materiais geológicos para a composição do solo construído em áreas de mineração de carvão. 1997. 186f. Tese (Doutorado em Agronomia - Ciências do Solo) Faculdade de Agronomia, Universidade Federal do Rio Grande do Sul.

POTTER, K.N. et al. Physical properties of constructed and undisturbed soils. Soil Science Society America Journal, v.52, p.1453-1438, 1988.

SENCINDIVER, J.C.; AMMONS, J.T. Mine soil genesis and classification. In: BARNHISEL, R. (Ed.). Reclamation of drastically disturbed lands. Madison:American Society of Agronomy, 2000. p.595-614.

SNARSKI, R.R. et al. Physical and chemical characteristics of pre-mine soils and post-mine soil mixtures in Illinois. Soil Science Society America Journal, v.45, p.806-812, 1981.

STATISTIX 7. Analytical Software. User's manual. Tallahassee, 2000. 396p.

TEDESCO, J.M. et al. Análise de solo, plantas e outros materiais. 2.ed. Porto Alegre:Departamento de Solos, UFRGS, 1995. 174p. (Boletim técnico n.5).

USDA - United States Department of Agriculture. Soil Survey Manual. Washington DC: Soil Survey Division Staff, 1993. 437p. 